\title{
Supportive Care of Breast Cancer Patients in Iran: A Systematic Review
}

\author{
Nasim Khosravi ${ }^{1}$, Najmeh Nazeri ${ }^{2}$, Vahid Farajivafa ${ }^{1}$, Asiie Olfatbakhsh ${ }^{2}$, Alireza Atashi ${ }^{3}$, Maryam \\ Koosha $^{2}$ and Shahpar Haghighat ${ }^{2,{ }^{*}}$
}

${ }^{1}$ Physical Education and Sport Sciences Department, Faculty of Humanities, Tarbiat Modares University, Tehran, Iran
${ }^{2}$ Breast Cancer Research Center, Motamed Cancer Institute, ACECR, Tehran, Iran
${ }^{3}$ E-Health Department, Virtual School, Tehran University of Medical Sciences, Tehran, Iran
'Corresponding author: Breast Cancer Research Center, Motamed Cancer Institute, ACECR, Tehran, Iran. Email: sha_haghighat@yahoo.com

"Corresponding author: Breast Cancer Research Center, Motamed Cancer Institute, AC
Received 2018 August 12; Revised 2019 March 17; Accepted 2019 March 18.

\begin{abstract}
Context: As breast cancer treatment going forward, need for supportive strategies grows. That creates an important call to summarize what has been done regionally.

Objectives: In this study, we systematically reviewed articles that proceeded rehabilitation and supportive care in breast cancer patients in Iran to present a research map of rehabilitation research in the past 10 years in Iran.

Data Sources: All articles published from January 2006 to October 2015 were included. All of the breast cancer studies in Iran were searched in 3 English (Web of Science, PubMed, and Scopus) and 2 Persian databases (SID and IranMedex).

Study Selection: All papers related to rehabilitation in breast cancer were included and categorized into 5 subgroups including qualitative, instrument, lymphedema, interventional, and observational studies. Three reviewers (two surgeons and an epidemiologist) screened the primary search and divided it into subgroups.

Data Extraction: Two reviewers used a checklist to critically appraise the full text of the selected articles. The necessary information of retrieved articles was extracted and recorded in the designed data extraction spreadsheet in Excel software.

Results: A total of 194 articles (102 in English and 92 in Persian) were assessed for eligibility of inclusion in the review, of which, 121 were excluded, and 73 studies were kept. The included studies consisted of 14 on qualitative design, 5 studies in the translation and validation of research instruments, 7 articles in the field of lymphedema, 20 articles about different intervention modalities on breast cancer patients (including education, social status, psychological, exercise, etc.), and 27 observational studies about anxiety, depression, quality of life, sexual function, emotional distress, complementary medicine, lifestyle, etc.

Conclusions: Most of the reviewed studies insisted on a prevalence of physical, psychological, functional, and spiritual problems of breast cancer survivors and their caregivers. Designing a mega project to offer a palliative and rehabilitation service package according to the needs of Iranian patients may become a priority in their health care system.
\end{abstract}

Keywords: Breast Cancer, Supportive Care, Iran, Systematic Review

\section{Context}

Breast cancer (BC) treatment exposes patients and their caregivers to a series of challenges that make coping with the situation a struggle. At the same time, the burden of the disease impacts society at large (1). Younger women with $\mathrm{BC}$ are more likely to experience psychosocial and menopause-related concerns, weight gain, and physical inactivity (2). The broad spectrum of psychosocial issues experienced by women with $\mathrm{BC}$ can be categorized into 4 groups, including (1) dealing with cancer, (2) the importance of caring, (3) the aftermath of cancer, and (4) fertility and infertility (3).

Owing to improvements in cancer detection and treatment, $\mathrm{BC}$ is increasingly becoming a chronic illness with longer survival years. Therefore, for $\mathrm{BC}$ rehabilitation to be comprehensive and effective, patients and their caregivers should be taught how to incorporate health-promoting habits in their lives by redesigning their lifestyles (4). There is strong evidence that BC patients and survivors can benefit enormously from exercise interventions in terms of quality of life (QoL), cardiorespiratory fitness, physical functioning, and fatigue $(5,6)$. For instance, yoga practice has been shown to enhance health and alleviates some treatment-related side effects for patients recovering from BC (7). In total, acknowledging practitioners and clinicians may help to improve a BC prognosis through recommending exercise, anticipating the physiological effects on cancer (8). 


\section{Objectives}

According to the published research, BC patients need various services during and after treatment in order to maintain a better QoL. It seems that most of these aspects are unclear in Iranian women. In this study, we systematically reviewed articles that begin with rehabilitation in BC patients in Iran. Presenting the research map of rehabilitation activity in the past 10 years in Iran may provide a useful perspective for future research to establish the efficient and beneficial services for developing the QoL of these patients.

\section{Methods}

This study is part of a big project to study the different aspects of BC in Iran. All of the published articles about BC in Iran, within a defined time, were included in the study. Then they were divided into 5 subgroups, and a specific process of systematic review was followed in each subgroup. Details of the methodology are as follow:

\section{Data Sources}

All articles published from January 2006 to October 2015 were included. To achieve the most comprehensive medical electronic databases, keywords were extracted from the medical subject headings (MeSH) of PubMed. Studies were searched in English and Persian databases. English online international electronic databases consisted of Web of Science, PubMed, and Scopus. The English search formula was "breast cancer" OR "breast carcinoma" OR "breast tumor" OR "breast neoplasm" AND "Iran". In total, 1986 English abstracts were included.

Persian databases consisted of SID and IranMedex, the most comprehensive national electronic databases, with the most coverage of Iranian public health and medical journals. It was not possible using a combined formula in a Persian search; so, keywords were searched separately (Saratan-e-Sineh, Saratan-e-Pestan, breast tumor, breast cancer, breast carcinoma, breast neoplasm and Iran). Then, they were combined with each other. In total, 1345 Persian abstracts were retrieved.

\section{Study Selection}

Three reviewers (two surgeons and one epidemiologist) screened the primary search and divided it into subgroups; 50 articles were randomly selected for validation of the reviewers' agreement assessment. They were instructed to decrease their disagreements in article classification. The trained experts divided the articles into 5 subgroups (epidemiology and risk factors, genetic, prevention, diagnosis and treatment, and rehabilitation), although some of them were allocated to more than one group. Being classified according to titles and abstracts, the duplicated and unrelated articles were excluded. Totally, 763 English and 572 Persian abstracts were divided into 5 subgroups to find and assess the full-texts. Irrelevant studies were evaluated again by the team supervisor. So, the final number of eligible articles for systematic review in 5 subgroups was 1646 abstracts. The full text of abstracts was found, and in some occasions, a letter was sent to the author to get the necessary information. Two reviewers used a checklist to critically appraise the full text of the selected articles. If there was any disagreement, the reviewers would discuss the eligibility of the articles and make a decision about it.

\section{Data Extraction}

The necessary information of retrieved articles was extracted and recorded in the designed data extraction spreadsheet in Excel software. Datasheet consisted of general information (title, the place of study, study year, journal name, and publication year), methodological information (study design, sample size, data source, studied population, measurement tools, sampling method), and results of the study (main outcome, effect size, and measurement tools). All of the articles were extracted by two people. A representative of each subgroup organized the two extracted forms into one sheet.

In the third step, the extracted data should be analyzed. Because of the variety in the field of studies, the results were categorized according to their study design, except for specific fields such as lymphedema and validation of instruments. Thus, the rehabilitation subgroup reviewed articles were categorized into 5 groups, including qualitative, instrument, lymphedema, interventional, and observational studies. Interventional studies were divided into educational, social, psychological, exercise, and other interventions. Observational studies consisted of anxiety and depression, QoL, sexual status, emotional distress, complementary medicine, and social studies.

\section{Results}

In total, 194 articles, consisting of 102 English and 92 Persian, were considered eligible for study in this group, of which 11 studies were duplicated and removed. From 183 studies, 83 studies were irrelevant and excluded. In the next step, more than 27 studies were excluded based on full text. The reasons for exclusion were as follows:

Nine articles were just abstracts, 7 were not specifically related to BC, 7 were review studies, 2 articles were not related to the Iranian population, and 2 studies were on animals (Figure 1). The reviewed articles were categorized into 5 groups according to their main themes. The results of the papers in each group were as follow: 


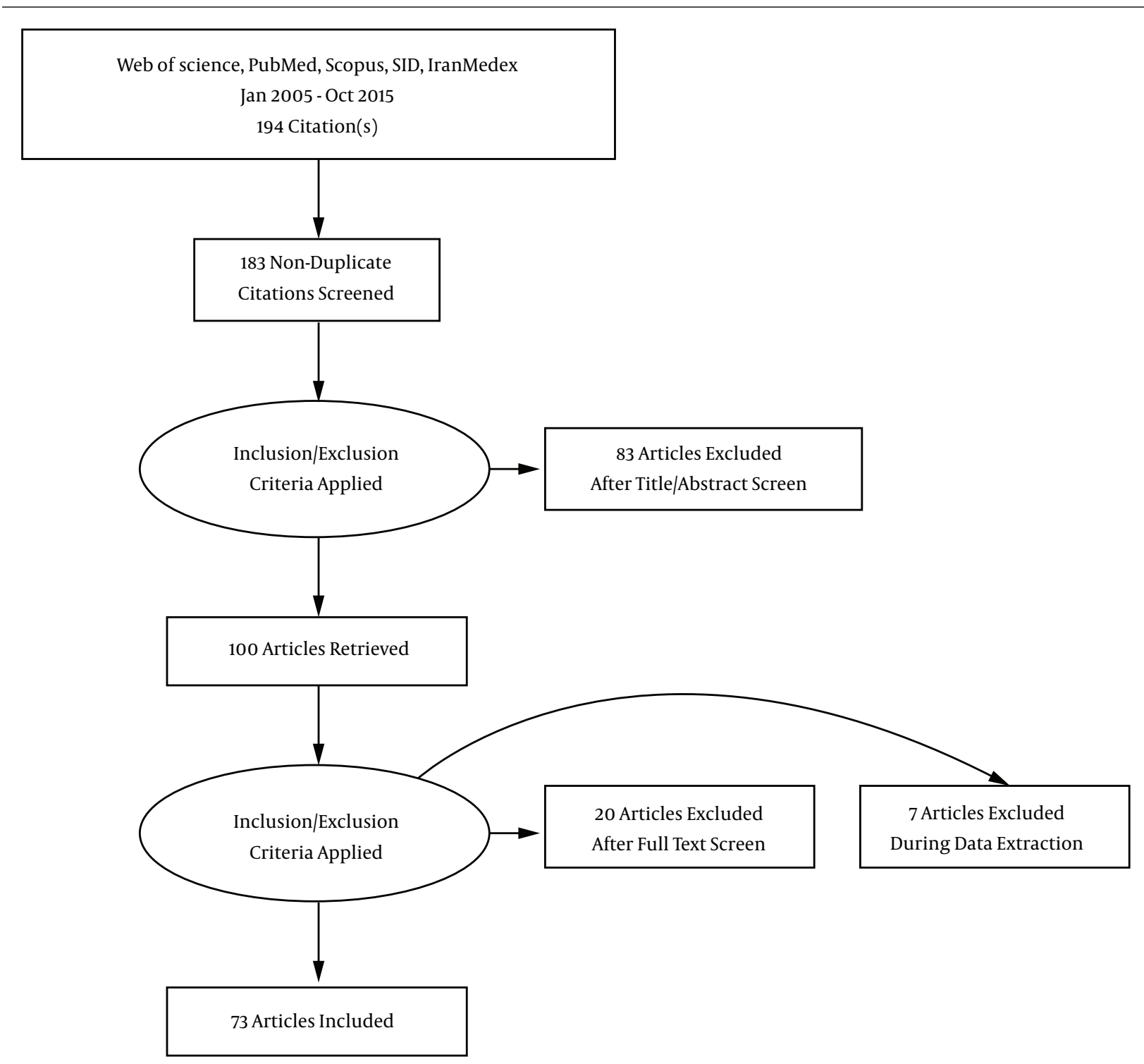

Figure 1. Flow diagram of studies

\subsection{Qualitative}

As qualitative studies must be analyzed differently in the systematic review, we are just reporting an overview of them. In total, 14 studies were conducted by qualitative design. All of these studies (9-20), except two (21, 22), were done on BC patients. A study was on BC caregivers. Different purposes were assumed for these studies. The assumed purposes were patients' needs $(14,18)$, caregivers experiences (22), their religious experience $(10,16)$, their experience with BC and symptoms $(12,13,17)$, coping with $\mathrm{BC}$ and treatment side effects $(9,19,20)$, their perceptions of life (15) and role of social and cultural factors in a patient's life (11), and the patient's husband's perception toward their sexual life (21). Different extracted articles in this theme have been presented in Table 1 .

\subsection{Instrument}

Articles in which different instruments had been translated and validated were categorized in another theme. In sum, we found 5 studies. All of them except one had studied BC patients (23-26). The other one had been conducted on the BC patient's caregivers (27). Most of the studies had validated an instrument in the field of QoL. FACT-B, mini MAC scale, need questionnaire, QoL index-cancer scales, and QLQ-C30 had been validated in these studies (Table 2). 


\begin{tabular}{|c|c|c|c|c|c|}
\hline Study & Sample Size & $\begin{array}{c}\text { Age, Mean } \pm \\
\text { SD }\end{array}$ & Age Range & Outcome of Interest & Main Extracted Themes \\
\hline Taleghani et al. (19) & 19 & $\mathrm{~N} / \mathrm{A}$ & $31-25$ & Coping with BC & $\begin{array}{l}\text { Religious approach, thinking about the } \\
\text { disease, accepting the disease, social and } \\
\text { cultural factors, support sources }\end{array}$ \\
\hline Taleghani (20) & 45 & $\mathrm{~N} / \mathrm{A}$ & $31-56$ & $\begin{array}{l}\text { Patient's experiences in } \\
\text { adjusting to the disease }\end{array}$ & $\begin{array}{l}\text { Perceived threat to life, living with the } \\
\text { disease with tolerance, religious aspects, } \\
\text { and barriers to efforts leading to health, } \\
\text { will to recover, supportive dimensions, } \\
\text { increase in endurance, and inhibitors and } \\
\text { facilitators of tolerance }\end{array}$ \\
\hline Harandy et al. (10) & 39 & $\mathrm{~N} / \mathrm{A}$ & $30-87$ & $\begin{array}{l}\text { Patient's experience with } \\
\text { religious context }\end{array}$ & $\begin{array}{l}\text { Religiosity does not prevent Iranian women } \\
\text { from seeking medical care }\end{array}$ \\
\hline Harandy et al. (11) & 39 & $\mathrm{~N} / \mathrm{A}$ & $30-87$ & $\begin{array}{l}\text { Correlated factors of } \\
\text { health-related quality of life }\end{array}$ & $\begin{array}{l}\text { Fatigue, pain, and lymphedema are the } \\
\text { most common complaints }\end{array}$ \\
\hline Sajadian et al. (17) & 51 & $48.4 \pm 10.5$ & $25-72$ & Patient's experience with BC & $\begin{array}{l}\text { Importance of spirituality and family } \\
\text { support, especially husband and children, } \\
\text { during the diagnosis and treatment; } \\
\text { chemotherapy as the worst experience }\end{array}$ \\
\hline Nasrabadi et al. (15) & 23 & $\mathrm{~N} / \mathrm{A}$ & $\mathrm{N} / \mathrm{A}$ & Patient's perception of life & $\begin{array}{l}\text { Cancer as a kind of divine test, a very bitter } \\
\text { and debilitating experience, chemotherapy } \\
\text { as the most difficult experience of cancer, a } \\
\text { continuous struggle }\end{array}$ \\
\hline Joulaee et al. (12) & 13 & $\mathrm{~N} / \mathrm{A}$ & $34-67$ & Patient's experience with BC & $\begin{array}{l}\text { Negative aspects: losing something } \\
\text { important, uncertainty, living with fear, } \\
\text { emotional confusion, needing support, } \\
\text { positive aspects: new aspects of life }\end{array}$ \\
\hline Moradian et al. (14) & 30 & $42 \pm N / A$ & $19-59$ & Patients' needs & Treatment costs, psychological distress \\
\hline Nasiri et al. (21) & 18 & $51.5 \pm 10.47$ & $33-70$ & $\begin{array}{l}\text { Patient's husband } \\
\text { perceptions }\end{array}$ & $\begin{array}{l}\text { Altered sexual relations; sexual abstinence, } \\
\text { avoidance, or restraint; attempt to } \\
\text { normalize relationship }\end{array}$ \\
\hline Fouladi et al. (9) & 20 & $\mathrm{~N} / \mathrm{A}$ & $33-71$ & Coping with mastectomy & $\begin{array}{l}\text { Loss and death contest, reconstruction of } \\
\text { evaluation system, reactions and troubles } \\
\text { after a loss, health, reorganization and } \\
\text { compatibility with changes }\end{array}$ \\
\hline Khakbazan et al. (13) & 27 & $42.8 \pm N / A$ & $26-71$ & $\begin{array}{l}\text { Patient's experience with } \\
\text { symptoms }\end{array}$ & $\begin{array}{l}\text { Symptom recognition, confronting the fear } \\
\text { of cancer, labeling symptoms, interactive } \\
\text { understanding }\end{array}$ \\
\hline Sadati et al. (16) & 8 & $\mathrm{~N} / \mathrm{A}$ & $\mathrm{N} / \mathrm{A}$ & $\begin{array}{l}\text { Patient's experience with } \\
\text { religious context }\end{array}$ & Fatalism, hope, and empowerment \\
\hline Taleghani et al. (18) & 19 & $\mathrm{~N} / \mathrm{A}$ & $34-60$ & needs of patients & Information, beliefs, and skills \\
\hline $\begin{array}{l}\text { Hashemi-Ghasemabadi et } \\
\text { al. (22) }\end{array}$ & 23 & $37.5 \pm N / A$ & $20-69$ & Caregivers & $\begin{array}{l}\text { Being involved in a new situation, } \\
\text { abandoned in the role, infinite absence, } \\
\text { perceived inefficiency }\end{array}$ \\
\hline
\end{tabular}

\subsection{Lymphedema}

Seven studies (28-34) were conducted on BC patients, who suffered from lymphedema (Table 3 ). Although some of these studies were looking at lymphedema treatment methods, we tried to discuss the rehabilitation aspects because of their importance in BC QoL and rehabilitation of which 3 were interventional (29-31), and the remaining 4 were observational $(28,32,33)$. Two kinds of intervention were used in this field; 2 of them were a combination of complex decongestive therapy (CDT) vs. CDT + intermittent pneumatic compression (29, 31), and they both reported the significant effects of this method on BCrelated lymphedema. The third interventional study evaluated the effect of a home-based rehabilitation education on edema reduction (30). It also had a significant effect on lymphedema reduction.

\subsection{Interventional Studies}

In total, we found 20 articles, which looked at different intervention modalities on BC patients. These studies were conducted on distinct fields including education, social status, psychological, exercise, and other aspects. Those fields have been reported in Table 4 .

There were 3 papers in the education field $(37,40,53)$. Two, out of the 3 studies, were controlled trials $(40,53)$, and the 1 remaining was a trial without a control group (37). All 3 studies had a sample size of more than 50. One study found that a life skill educational program was associated with improvements in somatization disorders, depressive and anxiety symptoms, disorders of social functioning, and sleep disorders (53). Two other studies had looked at the effects of self-care education on QoL and mental health $(37,40)$. The results showed that self-care educa- 


\begin{tabular}{|c|c|c|c|c|c|}
\hline Study & $\begin{array}{l}\text { Sample } \\
\text { Size }\end{array}$ & Age, Mean \pm SD & $\begin{array}{c}\text { Age } \\
\text { Range }\end{array}$ & Validated Instrument & Main Result \\
\hline Safaee et al. (25) & 132 & $48.61 \pm 11.22$ & NA & QLQ-C30 & $\begin{array}{l}\text { Cronbach's alpha: fitted in all subscales except } \\
\text { fatigue (0.65), pain ( } 0.69) \text { and nausea and vomiting } \\
\text { (0.66). Convergent validity correlation: }>0.40 \text { for } \\
\text { all subscales. Item discriminant validity: significant } \\
\text { difference in all subscales except for item } 4 \text { of the } \\
\text { physical functioning }\end{array}$ \\
\hline Khanjari et al. (26) & 166 & $40.7 \pm 13.1$ & $18-75$ & $\begin{array}{l}\text { Caregiver quality of life } \\
\text { index-cancer scale }\end{array}$ & Cronbach's alpha: $0.72-0.90$ \\
\hline Ghaffari et al. (24) & 160 & $44.6 \pm 12.63$ & NA & $\begin{array}{l}\text { Self-assessed support needs } \\
\text { questionnaire for BC cases }\end{array}$ & $\begin{array}{l}\text { Cronbach's alpha for all items: } 0.83 \text {, stability of test: } \\
0.78 \text {, Cronbach's alpha of the first factor: } 0.90\end{array}$ \\
\hline Patoo et al. (23) & 300 & $43.34 \pm \mathrm{NA}$ & $23-72$ & $\begin{array}{l}\text { Functional assessment of } \\
\text { cancer therapy-breast (FACT-B) }\end{array}$ & $\begin{array}{l}\text { Cronbach's alpha (total): } 0.92 \text {, Cronbach's alpha } \\
\text { (subscales): } 0.63 \text { to } 0.93 \text {, significant concurrent and } \\
\text { discriminant validity was fitted. }\end{array}$ \\
\hline Patoo et al. (27) & 320 & NA & NA & $\begin{array}{l}\text { Mini-mental adjustment to } \\
\text { cancer scale (mini-MAC scale) }\end{array}$ & Cronbach's alpha: 0.84 \\
\hline
\end{tabular}

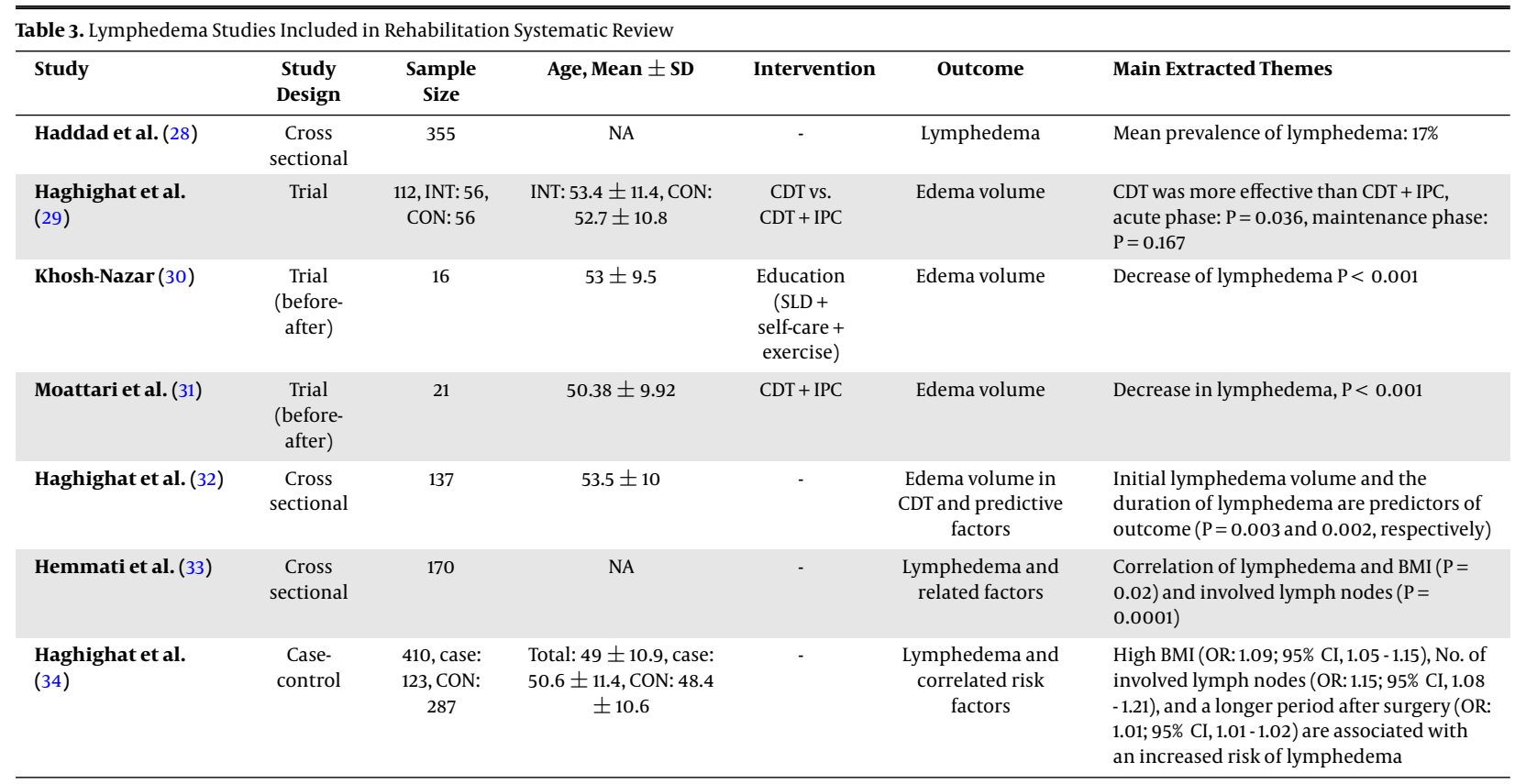

Abbreviations: CDT, complex decongestive therapy; IPC, intermittent pneumatic compression; SLD, self lymphatic drainage.

tional intervention was associated with the significant improvement of mental health (37); however, the other study reported non-significant changes in QoL (40).

Three studies looked at the effects of social intervention on the QoL of BC patients $(39,41,42)$. In all 3 studies, the intervention was participation in a peer support group. They studied the intervention effect on QoL. In total, social intervention had a significant effect on vitality, mental health, and the total score of QoL.

We found 8 studies that had investigated the effects of psychological interventions on BC patients. All 8 studies were done on $\mathrm{BC}$ patients. Five out of 8 studies had a sample size between 20 and $30(43,45,50,51,54)$. Two studies had sample sizes of more than $50(38,44)$. A variety of psychological interventions were used; a complete list of interventions is presented in Table 4. Three different kinds of outcomes were assessed including $\operatorname{QoL}(43,44,52,54)$, body image $(38,45,51)$, and depression (50). Interestingly, all psychological interventions led to improvement in the selected outcomes.

Two papers had used exercise as an intervention (36, 46). One of them had measured physiological indices (36) and the other one measured QoL (46). Exercise had a significant effect on physiological outcomes (36) related to cardiopulmonary fitness. The other study reported no significant effect on QoL (46). 
One study looked at exercise plus ginger supplementation on cardiopulmonary and IL-10. Results of the study showed that this intervention had a significant effect on the selected outcomes (47). One study looked at the effect of ginger supplement on nausea and the result showed a significant effect of ginger on nausea (49). Also, there was a study about the effect of massage therapy on nausea and its result showed no significant effect (48). Finally, one study had looked at the effect of a rehabilitation intervention on QoL and result showed significant improvement in all subscales of QoL (35).

\subsection{Observational Studies}

In total, 27 studies had been conducted by observational design. All of these studies except 4 were performed on $\mathrm{BC}$ patients. Three of the mentioned studies were on BC caregivers and the 4 th was on cancer patients. Different purposes were assumed for these studies. The main purposes of these studies were anxiety $(55,56)$, depression (5557), QoL (58-64), sexual status (65-67), emotional distress (68), caregiver's QoL (69-71), complementary use status (72, 73), QoL status relationship with lifestyle (74), QoL relationship with nutritional status (75), QoL status along with sense of coherence (76), the relationship between quality of sleep and with spiritual well-being (77), the relationship between hope, body esteem, and mental health (78), QoL status relationship with spiritual well-being (79), and social $(80,81)$. Also, different themes were extracted that are presented in Table 5. In all of these groups of articles, the frequency of outcome, its range of variation during a time interval, and some of their correlated factors in a specified sample size had been reported.

\section{Discussion}

The aim of this study was presenting all of the articles that had studied Iranian BC patients and looked at outcomes related to HRQoL. In total, we found 73 studies. As studies were so varied, we divided them to 5 parts, including qualitative, instrument, lymphedema, interventional, and observational studies. Interventional and observational studies contained different structures.

\subsection{Qualitative Studies}

Though we present the results of the qualitative studies, the conclusions of these studies were not presented because the method for reviewing these kinds of studies is different than in quantitative studies (72). Thus, there is just a report of them. Qualitative studies were conducted on BC patients and also on their caregivers. Such different themes were extracted that a discussion on these themes is beyond the scope of this article. In these studies, different goals were followed, including general experience and perspective, religious experience, ways of coping, their needs, and the role of other factors in that experience (9-22). Only two of 14 articles were about husbands (21) and caregivers (22). Unfortunately, none of the qualitative studies have led to a quantitative guideline for future studies. Developing some native quantitative instruments for the evaluation of patients' needs or experiences is suggested to provide applicable guidelines for the promotion of rehabilitation services.

\subsection{Instruments Validation}

This review introduced 5 Iranian validated questionnaires for evaluating QoL (QLQ-C30), the caregiver QoL index-cancer scale, self-assessed support needs questionnaire for breast cancer cases, mini-mental adjustment to cancer scale (Mini-MAC scale), and functional assessment of cancer therapy-breast (FACT-B) (23-27). It is possible that some instruments have been validated before this time interval or might have been published in some references that have not been included in this study. The development of more valid and reliable instruments in different aspects of cancer rehabilitation can present a more accurate measurement of problems and provide more effective interventions for solving them. Thus, it seems that introducing native and national valid instruments should be considered in future researches.

\subsection{Lymphedema}

Breast cancer patients often experience lymphedema, which could compromise their QoL and interfere with their daily activities $(65,73)$. A mean prevalence of $17.5 \%$ was reported for Iranian $\mathrm{BC}$ patients according to one study (28). The prevalence of BC-related lymphedema had been reported at $6 \%$ to $70 \%$, depending on the kind of surgery (64). Despite a lot of studies about lymphedema in the world, it still has many unknown aspects (82). In Iran, lymphedema treatment started 13 years ago. During this time, only a few clinics have been involved in treatment. So, very limited research is accessible. Among 7 studies presented in this systematic review, 3 clinical trials and 4 observational studies have been published. Risk factors of lymphedema have been studied in 2013. It showed that body mass index (BMI) and the numeration of involved lymph nodes were significantly related to BC-related lymphedema incidence (33). The standard method for controlling lymphedema is CDT or complete decongestive therapy (82). CDT results have been evaluated in limited studies. Though outcomes and methods of studies reviewed were completely different, 2 studies indicated that a combined decongestive therapy and pneumatic compression pump reduce the BC-related lymphedema $(29,31)$. In a study, it was shown that initial lymphedema volume and duration of lymphedema were important predictive factors for edema volume reduction following decongestive therapy (32). Also, a home-based rehabilitation that contains drainage, exercise, and behavioral practice education 
was reported significantly effective in reducing BC-related mild lymphedema (30). Presented articles insisted on the valuable effects of CDT in controlling lymphedema. Definitely, more studies are warranted to study the epidemiology, risk factors, prognostic factors, and effective modalities for diagnosis and treatment of lymphedema in the Iranian population.

\subsection{Interventional Studies}

Reviewed studies revealed that educational programs could increase patients' QoL and mental health $(37,40,53)$. The results of reviewed studies were similar to other studies, which indicated self-care educational programs have an important role in promoting QoL and decreasing mental distress after a BC diagnosis (56). A self-care concept or life skill education consisted of different parts. In the reviewed studies, the details of interventions were somehow less than expected (63), so more studies with exact definitions of interventions are warranted. Finally, all 3 studies used traditional educational programs. As technology is integrating into our lives very quickly, it is suggested to conduct a technology-based educational program for BC patients, who often have difficulty to attend in individual classes. We found 3 studies in social part. In the reviewed article, all social interventions were about the effects of participation in a peer support group $(39,41,42)$. One study indicated that this kind of intervention has a significant effect on all aspects of QoL (41); however, other studies reported its significant effect on vitality and mental health (39). Regarding the positive effect of this kind of interventions in improving QoL, designed clinical trials with various social interventions and distinct outcomes are necessary to give better insight into the effects of that on BC.

Studies categorized in psychological groups had used different interventions. Two studies conducted mindfulness-based interventions, and the results showed that these kinds of psychological modalities promote QoL and decrease fatigue $(52,54)$. Also, innovative relaxation therapies, like the Benson relaxation method, were used and claimed that these methods improved the QoL, although their effect size had not been reported clearly (43). Spiritual therapy was among the other psychological interventions for improving the QoL (45). In addition, one researcher studied the effect of Ellis's rational emotive behavior therapy (REBT) intervention on body image outcomes. The results showed that the intervention changed body image favorably (38). Also, in another study, existential group therapy was compared with a reality group therapy, and the results revealed that existential therapy was more effective than other group therapy methods in improving body image (45). Generally, as there were huge differences in intervention types, we could not have a consensus; however, studies show that psychological interventions have an important role in enhancing QoL and body image after a $\mathrm{BC}$ diagnosis. Comparing their effects in controlled clinical trials can individualize the treatments and present the most effective methods in each patient.

Two studies looked at the effect of exercise intervention on BC outcomes. In one study, it was revealed that exercise could improve cardiopulmonary measures (36). Another study assessed the effect of exercise on QoL (46). The results of this study reported no significant effect of exercise on QoL. In another study, the effect of a combined exercise and ginger supplement on IL-10 and cardiopulmonary indices was compared (47). The results of the current study reveal that this combined exercise was associated with improvement in cardiopulmonary and immunity indices. According to McNeely, larger trials with a greater focus on study quality, adverse effects, and long-term benefits of exercise are needed to introduce more beneficial rehabilitation methods in BC patients (5). Some of conflicting results show that we need more studies to define proper exercise programs for BC patients and survivors in different steps of treatment.

Decreasing chemotherapy inducing nausea has been evaluated in different researches. Ginger supplements (49) and massage therapy (48) have been introduced as effective interventions for decreasing nausea in 2 studies. Only one article had studied the application of a rehabilitation program on QoL and it had resulted in a significant effect on outcome of interest (35).

\subsection{Observational Studies}

\subsubsection{Anxiety and Depression}

According to our results, 3 studies were focused on anxiety and depression as main outcomes. Vahdaninia et al. (55) evaluated anxiety and depression, using the hospital anxiety and depression scale before treatment, 3 months after initial treatment, and 1 year after the completion of treatment. According to the findings, anxiety improved over time. Hadi et al. (56) evaluated anxiety and depression, using the symptom checklist-90 revised (SCL-90R) in $\mathrm{BC}$ cases and control (healthy) groups. The mean score of anger subscales was significantly higher in the control group compared to cases. Younger patients had higher anger mean scores. Education and tumor size correlated significantly with anxiety. Mashhadi et al. (57) evaluated depression, using the Beck Depression Inventory (BDI) in cancer patients. Findings showed a significantly higher prevalence of depression in patients with BC. According to Vahdaninia et al. (55), depression improved over time. In Hadi et al.'s study (56), depression was not significantly different between the 2 age groups, and higher depression mean scores were found among younger patients. These 3 studies used different instruments with different methods, but the common limitation was a disability to differentiate the anxiety and depression caused by cancer or other factors. We need more ecological studies to deter- 
mine the anxiety and depression status in cancer patients and general population.

\subsubsection{Quality of Life}

The largest group of studies evaluated QoL. QLQ-C30 is the most current questionnaire to measure QoL in Iranian studies. These studies focused on patients and their caregiver's $Q$ QL and it is relationship with various variables. Tirgari et al. (58) pointed out that a mastectomy in BC participants induced a low mood state and QoL. Safaee et al. (59) mentioned that all symptoms' scores had a reverse association with QoL except loss of appetite and diarrhea. Pourhoseingholi et al. (64) introduced tumor grade, employment, financial status, menopausal status, and dyspnea as the major predictors of patients' QoL. Didehdar Ardebil et al. (60) studied HRQoL, using the Persian version of FACT-B. Frequency of depression symptoms was reported in $50 \%$ of the subjects. Significant correlation was observed between depression and overall HRQoL and between different modalities of treatments. Qol of patients treated by chemotherapy was significantly better than radiotherapy. Also, Hatam et al. (61) and Kiadaliri and Bastani (63) both reported a decrease in HRQoL due to chemotherapy with TAC more than a FAC regime. Musarezaie et al. (62) mentioned that QoL is inversely correlated with the no. of chemo sessions and educational status. Mohammadi et al. (74) reported that healthy eating practices were associated with higher scores on social, role, cognitive, and emotional scales, global QoL, and reduced symptoms of financial difficulties. Also, physical activity was significantly correlated with emotional and cognitive scales. These researchers in their other papers (75) reported significant correlations between nutritional status parameters and quality of life subscales: physical, emotional, cognitive, global QoL, symptoms scales fatigue, nausea/vomiting, pain, dyspnea, insomnia, appetite loss, constipation and diarrhea. Rohani et al. (76) reported that women with BC tended to score worse on physical and role scales, along with fatigue and financial difficulties, during the first 6 months when compared with healthy women. The sense of coherence (SOC) and baseline scores on several dimensions of HRQoL were the most important predictors of HRQoL changes. Jafari et al. (79) reported a significant, positive correlation between global QoL and spiritual well-being. Exercise can be an effective strategy to improve QoL in women with BC. It seems that most of the studies observe the effect of BC and its treatment modalities on QoL fluctuations. None of them have suggested a protocol for improving the QoL during the diagnosis and treatment processes. It is not clear if measuring the QoL index is the main problem or not? Is the measurement instrument appropriate in our population? It seems that special demographic characteristics, beliefs, and behaviors of our patients should be considered in new research instruments in order to suggest more applicable and useful interventions.
According to previous studies, exercise reduces fasting insulin levels in $\mathrm{BC}$ survivors. This may be due to exerciseinduced reductions in body weight. Practitioners and clinicians may better help BC prognosis be improved through exercise, anticipating physiological effects on cancer (8). Future research is necessary to determine optimal exercise modes and parameters (6). According to the mentioned articles' results, patient's QoL are affected by several factors. Therefore, we need more proportional attention to patients according their chemotherapy plan. Psychological consultation, exercise programs, nutritional advice, and educational programs may be helpful to improve patients' QoL.

Caregivers' QoL showed a negative correlation with depression (69). Family caregivers of $\mathrm{BC}$ patients are reported to be affected by psychological impacts for up to 6 months after the diagnosis (70). Caregiver's QoL improves over time (71). Family members as main caregivers should be empowered in order to prepare strong support for cancer patients in all steps. It seems that more studies and educational programs should be designed in future research.

Khoramirad et al. (77) showed the relationship between quality of sleep with spiritual well-being and religious activities; even though it was not significant. Heidari et al. (78) reported a significant relationship between body esteem with hope and mental health. There was a positive correlation between hope and mental health too.

\subsubsection{Sexual Status}

Garrusi and Faezee (65) studied BC patients' sexual status in 2008. She showed that desire was diminished in $70.6 \%$ of the women. The number of instances of coitus decreased in approximately $15 \%$ of the participants. About $30 \%$ of women reported lubrication and arousal problems, and $72 \%$ reported decreased orgasms. Sexual satisfaction did not have a significant correlation with orgasm. Harirchi et al. (66) reported pre-treatment and post-treatment sexual dysfunction rates to be $52 \%$ and $84 \%$, respectively, indicating a significant deterioration in sexual function among BC patients. A younger age, reception of endocrine therapy, and poor sexual function at pretreatment were the most significant contributing factors to post-treatment sexual disorders. Safarinejad et al. (67) mentioned the significant prevalence of lubrication problems, satisfaction disorder, desire disorder, and arousal disorder in $\mathrm{BC}$ patients compared with healthy controls. Patients receiving hormone therapy were more likely to experience sexual dysfunctions; therefore, this group of patients needed more attention and sexual therapy during and after treatment. It seems that there has been limited research in the study of frequent sexual dysfunctions in $\mathrm{BC}$ patients, but no intervention has been tried or suggested to solve this common problem. 


\subsubsection{Emotional Distress}

Saeedi-Saedi et al. (68) reported that $39 \%$ of the BC patients had severe emotional distress, which was significantly associated with lower functional status. Taking care of children, anxiety, fear, difficulty taking bath and wearing clothes, family issues, fever, and nasal dryness were the most common contributors to emotional distress. Designing some longitudinal research or clinical trials to evaluate important interventions to manage these unpleasant symptoms is necessary. Yoga practice has been shown to improve health and helps alleviate some treatment-related side effects in BC survivors (7).

\subsubsection{Complementary Medicine}

Montazeri et al. reported a significant association between depression and the use of complementary medicine (72). The use of complementary medicine among Iranian patients is not common; however, it is correlated with fear, anxiety, and mental distress (73). Leggett et al. reported evidence of different qualities to support that Guarana and Ganoderma lucidum may improve fatigue, while glutamine may be effective in improving oral mucositis symptoms. Overall, current evidence does not provide definitive recommendations regarding the effectiveness of complementary or alternative medicine in women with BC (83). Considering that there is a lack of effective chemotherapy-induced peripheral neuropathy interventions, natural products and complementary therapies merit further investigation (84). We need more trials to approve the effectiveness of complementary medicine in the Iranian population.

\subsubsection{Social}

Azarkish et al. (80) mentioned that older patients and those with longer work experience were less likely to return to work, while women with no pain, surgery scar, or lymphedema after the $\mathrm{BC}$ treatment were more likely to return to work. Moghaddam Tabrizi et al. reported a significant relationship between general health and a healthpromoting lifestyle (81). "Return to life" is an important goal in BC patients, which has not been studied in Iranian research. Fortunately, at present in Iran, most of the diagnosis and treatment modalities are accessible. It can lead to early diagnosis and higher survival in these patients; so, the frequency of survivors is increasing. Designing some projects to define a useful protocol to provide a high QoL for these survivors and a return to familial and social roles may be an important health priority.

To our knowledge, it is the first study that attempted to look at all of the different aspects of BC in Iran. The result of that study could help to draw a better framework to promote QoL of BC patients. Also, this study has some limitations. As our goal was gathering all of the studies done in Iran, some Iranian databases were searched. Despite their great contents, their search engines were some- how weak. Finally, numerous studies were selected and, then, divided into 4 parts. So, we have to discuss all QoL and rehabilitation-related studies in one article, although distinct designs were used by the included studies.

\section{Conclusions}

Several main problems have been demonstrated in Iranian studies about BC patients' rehabilitation. Most of them consist of the prevalence of physical, psychological, functional, and spiritual problems of BC survivors and their caregivers. More interventional trials in the fields of social aspects, emotional distress, complementary medicine, psychological and family consultations, exercise programs, nutritional plans and educational programs are necessary. Designing a mega project to offer a palliative rehabilitation service package according to the need of Iranian patients may be a priority in their health care system.

\section{Acknowledgments}

This study is part of a big project to review systematically different aspects of breast cancer in Iran, sponsored by a grant of Roche Company. Researchers appreciate the financial support of the Roche Company in providing this valuable breast cancer road map for facilitating future researches in Iran.

\section{Footnotes}

Authors' Contribution: Nasim Khosravi, Najmeh Nazeri, Shahpar Haghighat, Alireza Atashi, Vahid Farajivafa, Asiie Olfatbakhsh, and Maryam Koosha participated in the literature search and data extraction. Nasim Khosravi, Najmeh Nazeri, Vahid Farajivafa, and Shahpar Haghighat analyzed the data and prepared the manuscript. All authors read and approved the final manuscript.

Conflict of Interests: The authors declare that they have no conflict of interest.

Ethical Approval: This article does not contain any studies with human participants or animals performed by any of the authors. This research has been approved in Ethical Committee of Breast Cancer Research Center, ACECR.

Funding/Support: This study is part of a mega project to review systematically different aspects of BC in Iran sponsored by a grant of Roche Company.

\section{References}

1. Di Lascio S, Pagani O. Is it time to address survivorship in advanced breast cancer? A review article. Breast. 2017;31:167-72. doi: 10.1016/j.breast.2016.10.022. [PubMed: 27871024]. 
2. Howard-Anderson J, Ganz PA, Bower JE, Stanton AL. Quality of life, fertility concerns, and behavioral health outcomes in younger breast cancer survivors: A systematic review. J Natl Cancer Inst. 2012;104(5):386-405. doi:10.1093/jnci/djr541. [PubMed: 22271773].

3. Campbell-Enns HJ, Woodgate RL. The psychosocial experiences of women with breast cancer across the lifespan: A systematic review. Psychooncology. 2017;26(11):1711-21. doi: 10.1002/pon.4281. [PubMed: 27648726].

4. Loh SY, Musa AN. Methods to improve rehabilitation of patients following breast cancer surgery: A review of systematic reviews. Breast Cancer (Dove Med Press). 2015;7:81-98. doi: 10.2147/BCTT.S47012. [PubMed: 25792854]. [PubMed Central: PMC4360828].

5. McNeely ML, Campbell KL, Rowe BH, Klassen TP, Mackey JR, Courneya KS. Effects of exercise on breast cancer patients and survivors: A systematic review and meta-analysis. CMAJ. 2006;175(1):3441. doi: 10.1503/cmaj.051073. [PubMed: 16818906]. [PubMed Central: PMC1482759]

6. Bicego D, Brown K, Ruddick M, Storey D, Wong C, Harris SR. Effects of exercise on quality of life in women living with breast cancer: A systematic review. Breast J. 2009;15(1):45-51. doi: 10.1111/j.15244741.2008.00670.x. [PubMed: 19120381].

7. Pan Y, Yang K, Wang Y, Zhang L, Liang H. Could yoga practice improve treatment-related side effects and quality of life for women with breast cancer? A systematic review and meta-analysis. Asia Pac J Clin Oncol. 2017;13(2):e79-95. doi:10.1111/ajco.12329. [PubMed: 25560636].

8. Kang DW, Lee J, Suh SH, Ligibel J, Courneya KS, Jeon JY. Effects of exercise on insulin, IGF axis, adipocytokines, and inflammatory markers in breast cancer survivors: A systematic review and meta-analysis. Cancer Epidemiol Biomarkers Prev. 2017;26(3):355-65. doi: 10.1158/10559965.EPI-16-0602. [PubMed: 27742668].

9. Fouladi N, Pourfarzi F, Ali-Mohammadi H, Masumi A, Agamohammadi M, Mazaheri E. Process of coping with mastectomy: A qualitative study in Iran. Asian Pac J Cancer Prev. 2013;14(3):2079-84. [PubMed: 23679322].

10. Harandy TF, Ghofranipour F, Montazeri A, Anoosheh M, Bazargan M, Mohammadi E, et al. Muslim breast cancer survivor spirituality: Coping strategy or health seeking behavior hindrance? Health Care Women Int. 2010;31(1):88-98. doi: 10.1080/07399330903104516. [PubMed: 20390638].

11. Harandy TF, Ghofranipour F, Montazeri A, Anoosheh M, Mohammadi E, Ahmadi F, et al. Health-related quality of life in iranian breast cancer survivors: A qualitative study. Appl Res Qual Life. 2010;5(2):121-32. doi: 10.1007/s11482-010-9097-3.

12. Joulaee A, Joolaee S, Kadivar M, Hajibabaee F. Living with breast cancer: Iranian women's lived experiences. Int Nurs Rev. 2012;59(3):362-8. doi: 10.1111/j.1466-7657.2012.00979.x. [PubMed: 22897187].

13. Khakbazan Z, Roudsari RL, Taghipour A, Mohammadi E, Pour RO. Appraisal of breast cancer symptoms by Iranian women: Entangled cognitive, emotional and socio-cultural responses. Asian PacJ Cancer Prev. 2014;15(19):8135-42. [PubMed: 25338996].

14. Moradian S, Aledavood SA, Tabatabaee A. Iranian cancer patients and their perspectives: A qualitative study. Eur J Cancer Care (Engl). 2012;21(3):377-83. doi: 10.1111/j.1365-2354.2011.01293.x. [PubMed: 21955041].

15. Nasrabadi AN, Bahabadi AH, Hashemi F, Valiee S, Seif H. Views of Iranian patients on life with cancer: A phenomenological study. Nurs Health Sci. 2011;13(2):216-20. doi: 10.1111/j.1442-2018.2011.00604.x. [PubMed: 21595817].

16. Sadati AK, Lankarani KB, Gharibi V, Fard ME, Ebrahimzadeh N, Tahmasebi S. Religion as an empowerment context in the narrative of women with breast cancer. I Relig Health. 2015;54(3):1068-79. doi: 10.1007/s10943-014-9907-2. [PubMed: 25008190].

17. Sajadian A, Montazeri A. [Exploring the experiences of Iranian women with breast cancer: A qualitative study]. Iran JEpidemiol.2011;7(2):8-16. Persian.

18. Taleghani F, Bahrami M, Loripoor M, Yousefi A. Empowerment needs of women with breast cancer: A qualitative study. Iran Red Crescent Med J. 2014;16(11). e16379. doi: 10.5812/ircmj.16379. [PubMed: 25763213]. [PubMed Central: PMC4329958].

19. Taleghani F, Yekta ZP, Nasrabadi AN. Coping with breast cancer in newly diagnosed Iranian women. $J$ Adv Nurs. 2006;54(3):26572. discussion 272-3. doi: 10.1111/j.1365-2648.2006.03808_1.x. [PubMed: 16629910].

20. Taleghani F, Yekta ZP, Nasrabadi AN, Kappeli S. Adjustment process in Iranian women with breast cancer. Cancer Nurs. 2008;31(3):E32-41. doi: 10.1097/01.NCC.0000305720.98518.35. [PubMed:18453870].

21. Nasiri A, Taleghani F, Irajpour A. Men's sexual issues after breast cancer in their wives: A qualitative study. Cancer Nurs. 2012;35(3):236-44 doi:10.1097/NCC.0b013e31822d48e5. [PubMed: 22538261].

22. Hashemi-Ghasemabadi M, Taleghani F, Yousefy A, Kohan S. Transition to the new role of caregiving for families of patients with breast cancer: A qualitative descriptive exploratory study. Support Care Cancer. 2016;24(3):1269-76. doi: 10.1007/s00520-015-2906-3. [PubMed: 26306519].

23. Patoo M, Allahyari AA, Moradi AR, Payandeh M. Persian version of functional assessment of cancer therapy- breast (FACT-B) scale: Confirmatory factor analysis and psychometric properties. Asian Pac Cancer Prev. 2015;16(9):3799-803. [PubMed: 25987040].

24. Ghaffari F, Shali M, Shoghi M, Joolaee S. Psychometric properties of the Persian version of the self- assessed support needs questionnaire for breast cancer cases. Asian Pac J Cancer Prev. 2014;15(3):1435-40. [PubMed: 24606479].

25. Safaee A, Moghim Dehkordi B. Validation study of a quality of life (QOL) questionnaire for use in Iran. Asian Pac J Cancer Prev. 2007;8(4):543-6. [PubMed: 18260726].

26. Khanjari S, Oskouie F, Langius-Eklof A. Psychometric testing of the caregiver quality of life index-cancer scale in an Iranian sample of family caregivers to newly diagnosed breast cancer women. J Clin Nurs. 2012;21(3-4):573-84. doi: 10.1111/j.1365-2702.2011.03850.x. [PubMed: 21923672].

27. Patoo M, Allahyari AA, Moradi AR, Payandeh M. Iranian version of the mini-mental adjustment to cancer scale: Factor structure and psychometric properties. J Psychosoc Oncol. 2015;33(6):675-85. doi 10.1080/07347332.2015.1082169. [PubMed: 26600241].

28. Haddad P, Farzin M, Amouzegar-Hashemi F, Kalaghchi B, Babazadeh $S$, Mirzaei HR, et al. A multicentre cross-sectional study of arm lymphedema four or more years after breast cancer treatment in Iranian patients. Breast Cancer. 2010;17(4):281-5. doi: 10.1007/s12282-009-01651. [PubMed: 19789952].

29. Haghighat S, Lotfi-Tokaldany M, Yunesian M, Akbari ME, Nazemi F, Weiss J. Comparing two treatment methods for post mastectomy lymphedema: Complex decongestive therapy alone and in combination with intermittent pneumatic compression. Lymphology. 2010;43(1):25-33. [PubMed: 20552817]

30. khosh-Nazar T, Mohamadi F, Khankeh H, Haghighat S. [The effect of home based rehabilitation on volume edema, activity daily in breast cancer survivor's]. Iran QJ Breast Dis. 2010;3(3):34-42. Persian.

31. Moattari M, Jaafari B, Talei A, Piroozi S, Tahmasebi S, Zakeri Z. The ef fect of combined decongestive therapy and pneumatic compression pump on lymphedema indicators in patients with breast cancer related lymphedema. Iran Red Crescent Med J. 2012;14(4):210-7. [PubMed: 22754683]. [PubMed Central: PMC3385799].

32. Haghighat S, Lotfi-Tokaldany M, Maboudi AA, Karami M, Bahadori A Weiss J. Predictive factors of response to phase I complete decongestive therapy in upper extremity lymphedema following breast carcinoma in Iran. Lymphology. 2013;46(2):97-104. [PubMed: 24354108].

33. Hemmati S, Jabbari H, Akbari M, Tajvidi M, Rankoohi PA. [Factors associated with the severity of lymphedema after the treatment of invasive breast cancers]. J Isfahan Med Sch. 2013;30(211). Persian.

34. Haghighat S, Akbari A, Ansari M, Homaei Shandiz F, Najafi M Ebrahimi M, et al. Risk factors of lymph edema in breast cancer patients. Int J Breast Cancer. 2013;2013:641818. doi: 10.1155/2013/641818. [PubMed: 23862068]. [PubMed Central: PMC3687507].

35. Poorkiani M, Abbaszadeh A, Hazrati M, Jafari P, Sadeghi M, Mohammadianpanah $\mathrm{M}$. The effect of rehabilitation on quality of life in female breast cancer survivors in Iran. Indian J Med Paediatr Oncol. 2010;31(4):105-9. doi: 10.4103/0971-5851.76190. [PubMed: 21584214]. [PubMed Central: PMC3089917].

36. Rahnama N, Nouri R, Rahmaninia F, Damirchi A, Emami H. The effects 
of exercise training on maximum aerobic capacity, resting heart rate, blood pressure and anthropometric variables of postmenopausal women with breast cancer. J Res Med Sci. 2010;15(2):78-83. [PubMed: 21526063]. [PubMed Central: PMC3082798].

37. Bakhtiary M, Eslami M, Fesharaki M, Koosha S. [Effect of self care education on mental health of breast cancer women undergoing chemotherapy in cancer institute of Tehran]. Iran Q J Breast Dis. 2011;4(1):42-7. Persian.

38. Fadaei S, Janighorban M, Mehrabi T, Ahmadi SA, Mokaryan F, Gukizade A. Effects of cognitive behavioral counseling on body image following mastectomy. J Res Med Sci. 2011;16(8):1047-54. [PubMed: 22279481]. [PubMed Central: PMC3263082].

39. Malekpour Tehrani A, Farajzadegan Z, Rajabi FM, Zamani AR. Belonging to a peer support group enhance the quality of life and adherence rate in patients affected by breast cancer: A non-randomized controlled clinical trial. J Res Med Sci. 2011;16(5):658-65. [PubMed 22091289]. [PubMed Central: PMC3214378].

40. Ghavam-Nasiri MR, Heshmati Nabavi F, Anvari K, Habashi Zadeh A, Moradi M, Neghabi G, et al. [The effect of individual and group selfcare education on quality of life in patients receiving chemotherapy: A randomized clinical trial]. Iran JMed Educ. 2012;11(8):874-84. Persian.

41. Sharif F, Abshorshori N, Tahmasebi S, Hazrati M, Zare N, Masoumi S. The effect of peer-led education on the life quality of mastectomy patients referred to breast cancer-clinics in Shiraz, Iran 2009. Health Qual Life Outcomes. 2010;8:74. doi: 10.1186/1477-7525-8-74. [PubMed: 20653966]. [PubMed Central: PMC2919455].

42. Taleghani F, Babazadeh S, Mosavi S, Tavazohi H. The effects of peer support group on promoting quality of life in patients with breast cancer. Iran J Nurs Midwifery Res. 2012;17(2 Suppl 1):S125-30. [PubMed: 23833594]. [PubMed Central: PMC3696969].

43. Salehi M, Shariati A, Ansari M, Latifi M. [Effect of benson relaxation therapy on quality of life (qol) in breast cancer patients undergoing chemotherapy]. Jundishapur J Chronic Dis Care. 2012;1(1):1-8. Persian.

44. Jafari N, Zamani A, Farajzadegan Z, Bahrami F, Emami H, Loghmani A. The effect of spiritual therapy for improving the quality of life of women with breast cancer: A randomized controlled trial. Psychol Health Med. 2013;18(1):56-69. doi: 10.1080/13548506.2012.679738. [PubMed: 22533516].

45. Parizadeh H, Hasan Abadi H, Mashhadi A, Taghizadeh Kermani A. [Investigating effectiveness of existential and reality group-therapy in treatment of body-image problem in women who undergo mastectomy]. Iran J Obstet Gynecol Infertility. 2012;15(22):27-35. Persian.

46. Taleghani F, Karimain J, Babazadeh S, Mokarian F, Tabatabaiyan M, Samimi MA, et al. The effect of combined aerobic and resistance exercises on quality of life of women surviving breast cancer. Iran J Nurs Midwifery Res. 2012;17(1):47-51. [PubMed: 23493334]. [PubMed Central: PMC3590695].

47. Fathi Z, Dabidi Roshan V, Roodbari F. [The effects of IL-10 on myocardial protection protocols and cardiorespiratory parameters in obese women with breast cancer]. Iran J Diabet Lipid Disorder. 2012;12(1):6881. Persian.

48. Bosak S, Dashtbozorgi B, Hoseini M, Latifi M, Rezaei A. [The effect of massage therapy on nausea in patients who undergo chemotherapy for breast cancer]. Jundishapur J Chronic Dis Care. 2012;1(1):61-70. Persian.

49. Ebrahimi SM, Yekta ZP, Nikbakht-Nasrabadi A, Hosseini M, Sedighi $S$, Surmaghi MHS. [Assessment of palliative effects of ginger on chemotherapy-induced nausea: Delayed phase]. J Isfahan Med Sch. 2013;30(219). Persian.

50. Haghighi F, Khodaei S, Sharifzadeh GR. [Effect of logotherapy group counseling on depression in breast cancer patients]. Modern Care J. 2013;9(3):165-72. Persian.

51. Izadi-Ajirlo A, Bahmani B, Ghanbari-Motlagh A. [Effectiveness of cognitive behavioral group intervention on body image improving and increasing self-esteem in women with breast cancer after mastectomy]. J Rehabil. 2013;13(4):72-83. Persian.

52. Rahmani S, Talepasand S, Ghanbary-Motlagh A. Comparison of effectiveness of the metacognition treatment and the mindfulnessbased stress reduction treatment on global and specific life quality of women with breast cancer. Iran J Cancer Prev. 2014;7(4):184-96.
[PubMed: 25628839]. [PubMed Central: PMC4307101].

53. Shabani M, Moghimi M, Zamiri RE, Nazari F, Mousavinasab N, Shajari Z. Life skill training effectiveness on non-metastatic breast cancer mental health: A clinical trial. Basic Clin Cancer Res. 2012;4(1 \&amp; 2):21-9.

54. Rahmani S, Talepasand S. The effect of group mindfulness - based stress reduction program and conscious yoga on the fatigue severity and global and specific life quality in women with breast cancer. Med J Islam Repub Iran. 2015;29:175. [PubMed: 26034728]. [PubMed Central: PMC4431452].

55. Vahdaninia M, Omidvari S, Montazeri A. What do predict anxiety and depression in breast cancer patients? A follow-up study. Soc Psychiatry PsychiatrEpidemiol.2010;45(3):355-61. doi:10.1007/s00127-009-0068-7. [PubMed: 19458878].

56. Hadi N, Asadollahi R, Talei AR. Anxiety, depression and anger in breast cancer patients compared with the general population in Shiraz, southern Iran. Iran Red Crescent Med J. 2009;11(3):312-7.

57. Mashhadi MA, Shakiba M, Zakeri Z. Evaluation of depression in patients with cancer in south of Iran (Zahedan). Iran J Cancer Prev. 2013;6(1):12-6. [PubMed: 25250104]. [PubMed Central: PMC4142906].

58. Tirgari B, Iranmanesh S, Fazel A, Kalantari B. Quality of life and mood state in Iranian women post mastectomy. Clin J Oncol Nurs. 2012;16(3):E118-22. doi: 10.1188/12.CJON.E118-E122. [PubMed: 22641330].

59. Safaee A, Moghimi-Dehkordi B, Zeighami B, Tabatabaee H, Pourhoseingholi M. Predictors of quality of life in breast cancer patients under chemotherapy. Indian J Cancer. 2008;45(3):107-11. [PubMed: 19018114].

60. Didehdar Ardebil M, Bouzari Z, Shenas MH, Zeinalzadeh M, Barat S. Depression and health related quality of life in breast cancer patients. Acad J Cancer Res. 2011;4(2):43-6.

61. Hatam N, Bastani P, Ahmadloo N, Kiadaliri AA. [Health related quality of life in breast cancer patients undergoing current chemotherapy protocols]. J Kerman Univ Med Sci. 2012;19(1):49-58. Persian.

62. Musarezaie A, Ghasemi TM, Esfahani HN. Investigation the quality of life and its relation with clinical and demographic characteristics in women with breast cancer under chemotherapy. Int $J$ Prev Med. 2012;3(12):853-9. [PubMed: 23272284]. [PubMed Central: PMC3530303]

63. Kiadaliri A, Bastani P. Pcn136 quality of life after chemotherapy in breast cancer: A study in south of Iran. Value Health. 2010;13(7). A277. doi: 10.1016/s1098-3015(11)72031-9.

64. Pourhoseingholi MA, Safaee A, Moghimi-Dehkordi B, Zeighami B, Faghihzadeh S, Tabatabaee HR, et al. Quality of life in breast cancer patients: A quantile regression analysis. Asian Pac J Cancer Prev. 2008;9(3):487-90. [PubMed: 18990025].

65. Garrusi B, Faezee H. How do Iranian women with breast cancer conceptualize sex and body image? Sex Disabil. 2008;26(3):159-65. doi: 10.1007/s11195-008-9092-x.

66. Harirchi I, Montazeri A, Zamani Bidokhti F, Mamishi N, Zendehdel K. Sexual function in breast cancer patients: A prospective study from Iran.J Exp Clin Cancer Res. 2012;31:20. doi:10.1186/1756-9966-31-20. [PubMed: 22405489]. [PubMed Central: PMC3349561].

67. Safarinejad MR, Shafiei N, Safarinejad S. Quality of life and sexual functioning in young women with early-stage breast cancer 1 year after lumpectomy. Psychooncology. 2013;22(6):1242-8. doi: 10.1002/pon.3130. [PubMed: 22777952].

68. Saeedi-Saedi H, Shahidsales S, Koochak-Pour M, Sabahi E, Moridi I. Evaluation of emotional distress in breast cancer patients. Iran J Cancer Prev. 2015;8(1):36-41. [PubMed: 25821569]. [PubMed Central: PMC4360349].

69. Heidari Gorji MA, Bouzar Z, Haghshenas M, Kasaeeyan AA, Sadeghi MR, Ardebil MD. Quality of life and depression in caregivers of patients with breast cancer. BMC Res Notes. 2012;5:310. doi: 10.1186/17560500-5-310. [PubMed: 22715918]. [PubMed Central: PMC3407011].

70. Khanjari S, Langius-Eklof A, Oskouie F, Sundberg K. Family caregivers of women with breast cancer in Iran report high psychological impact six months after diagnosis. Eur J Oncol Nurs. 2014;18(6):630-5. doi: 10.1016/j.ejon.2014.06.002. [PubMed: 24996513].

71. Khanjari S, Oskouie F, Langius-Eklof A. Lower sense of coherence, negative religious coping, and disease severity as indicators of a 
decrease in quality of life in Iranian family caregivers of relatives with breast cancer during the first 6 months after diagnosis. Cancer Nurs. 2012;35(2):148-56. doi: 10.1097/NCC.0b013e31821fidda. [PubMed: 21760493].

72. Montazeri A, Sajadian A, Ebrahimi M, Akbari ME. Depression and the use of complementary medicine among breast cancer patients. Support Care Cancer. 2005;13(5):339-42. doi: 10.1007/s00520-004-0709-z. [PubMed: 15549425].

73. Montazeri A, Sajadian A, Ebrahimi M, Haghighat S, Harirchi I. Factors predicting the use of complementary and alternative therapies among cancer patients in Iran. EurJCancer Care (Engl). 2007;16(2):1449. doi: 10.1111/j.1365-2354.2006.00722.x. [PubMed: 17371423].

74. Mohammadi S, Sulaiman S, Koon PB, Amani R, Hosseini SM. Impact of healthy eating practices and physical activity on quality of life among breast cancer survivors. Asian Pac J Cancer Prev. 2013;14(1):4817. [PubMed: 23534778].

75. Mohammadi S, Sulaiman S, Koon PB, Amani R, Hosseini SM. Association of nutritional status with quality of life in breast cancer survivors. Asian Pac J Cancer Prev. 2013;14(12):7749-55. [PubMed: 24460363].

76. Rohani C, Abedi HA, Omranipour R, Langius-Eklof A. Health-related quality of life and the predictive role of sense of coherence, spirituality and religious coping in a sample of Iranian women with breast cancer: A prospective study with comparative design. Health Qual Life Outcomes.2015;13:40. doi:10.1186/s12955-015-0229-1.[PubMed: 25889384]. [PubMed Central: PMC4392858].

77. Khoramirad A, Mousavi M, Dadkhahtehrani T, Pourmarzi D. Relationship between sleep quality and spiritual well-being/religious activities in Muslim women with breast cancer. $J$ Relig Health 2015;54(6):2276-85. doi: 10.1007/s10943-014-9978-0. [PubMed:
25487182].

78. Heidari M, Ghodusi M. The relationship between body esteem and hope and mental health in breast cancer patients after mastectomy. Indian J Palliat Care. 2015;21(2):198-202. doi: 10.4103/0973-1075.156500. [PubMed: 26009674]. [PubMed Central: PMC4441182].

79. Jafari N, Farajzadegan Z, Zamani A, Bahrami F, Emami H, Loghmani A. Spiritual well-being and quality of life in Iranian women with breast cancer undergoing radiation therapy. Support Care Cancer. 2013;21(5):1219-25. doi: 10.1007/s00520-012-1650-1.[PubMed: 23138932]

80. Azarkish F, Mirzaii Najmabadi K, Latifnejad Roudsari R, Homaei Shandiz F. Factors related to return to work in women after breast cancer in Iran. Iran Red Crescent Med J. 2015;17(9). e19978. doi: 10.5812/ircmj.19978. [PubMed: 26473073]. [PubMed Central: PMC4601229].

81. Moghaddam Tabrizi F. Health promoting behavior and influencing factors in Iranian breast cancer survivors. Asian Pac J Cancer Prev. 2015;16(5):1729-36. [PubMed: 25773817].

82. International Society of $\mathrm{L}$. The diagnosis and treatment of peripheral lymphedema: 2013 consensus document of the International Society of Lymphology. Lymphology. 2013;46(1):1-11. [PubMed: 23930436].

83. Leggett S, Koczwara B, Miller M. The impact of complementary and alternative medicines on cancer symptoms, treatment side effects, quality of life, and survival in women with breast cancer: A systematic review. Nutr Cancer. 2015;67(3):373-91. doi: 10.1080/01635581.2015.1004731. [PubMed: 25811312].

84. Brami C, Bao T, Deng G. Natural products and complementary therapies for chemotherapy-induced peripheral neuropathy: A systematic review. Crit Rev Oncol Hematol. 2016;98:325-34. doi: 10.1016/j.critrevonc.2015.11.014. [PubMed: 26652982]. [PubMed Central: PMC4727999]. 


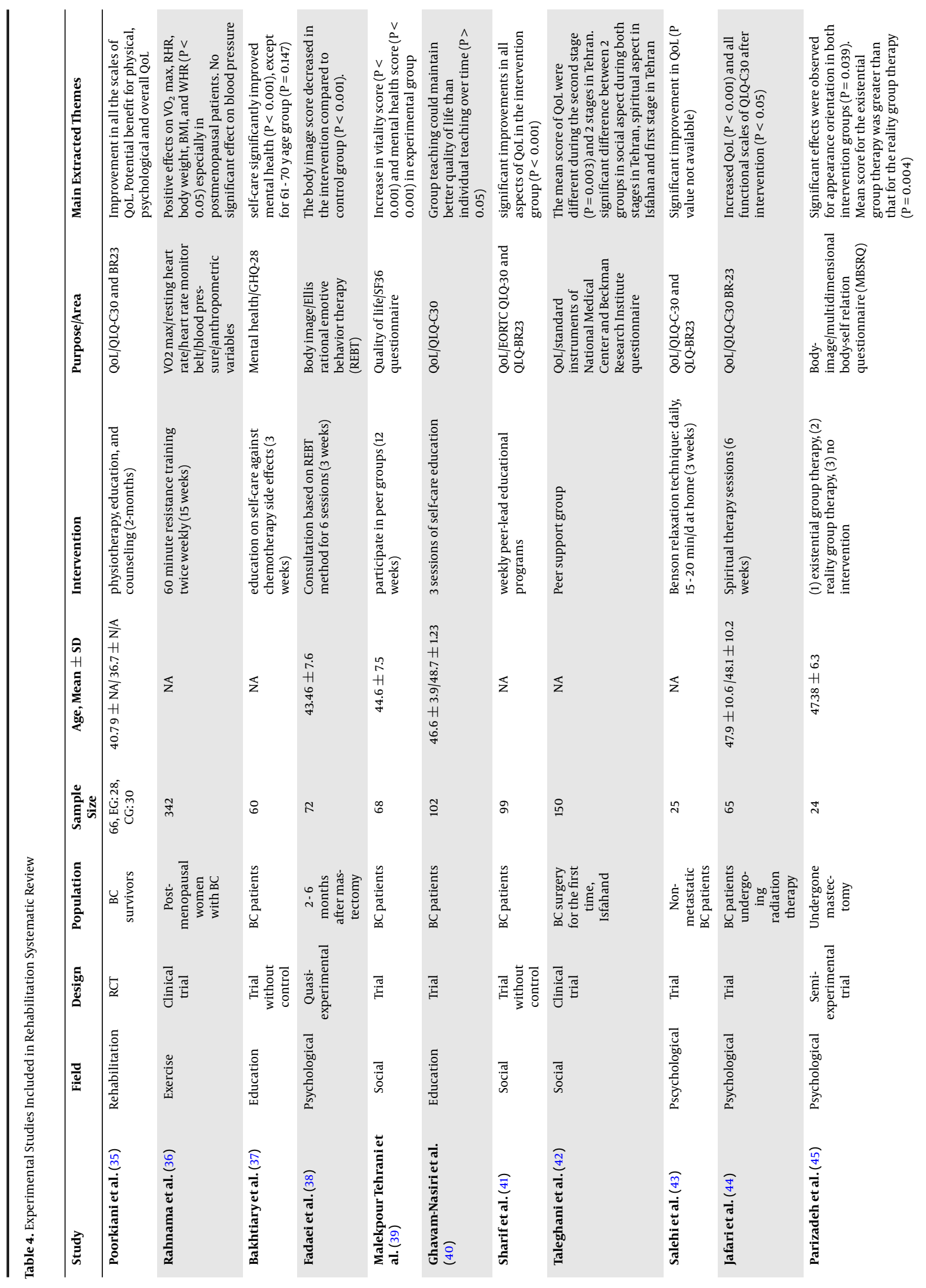




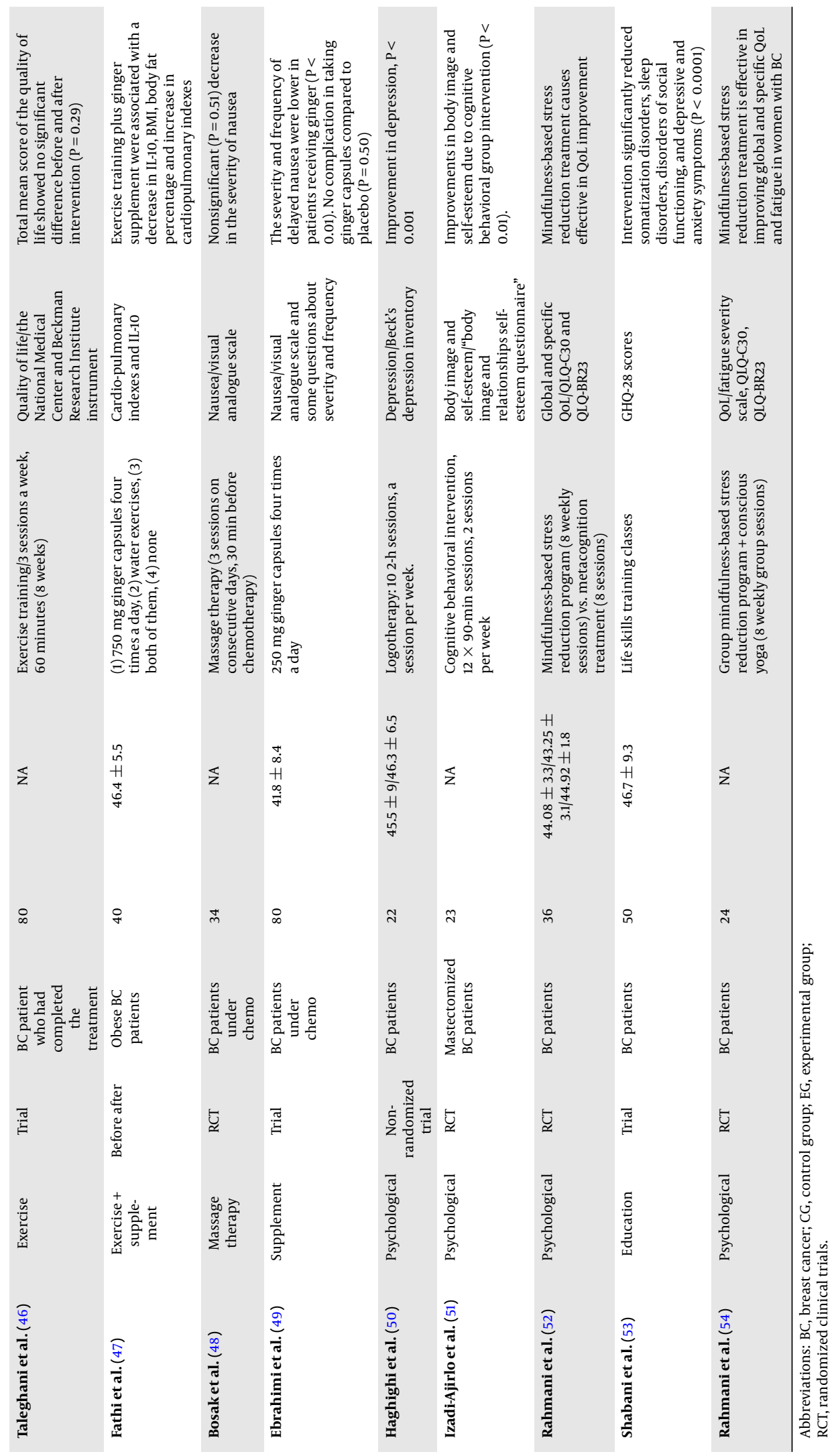




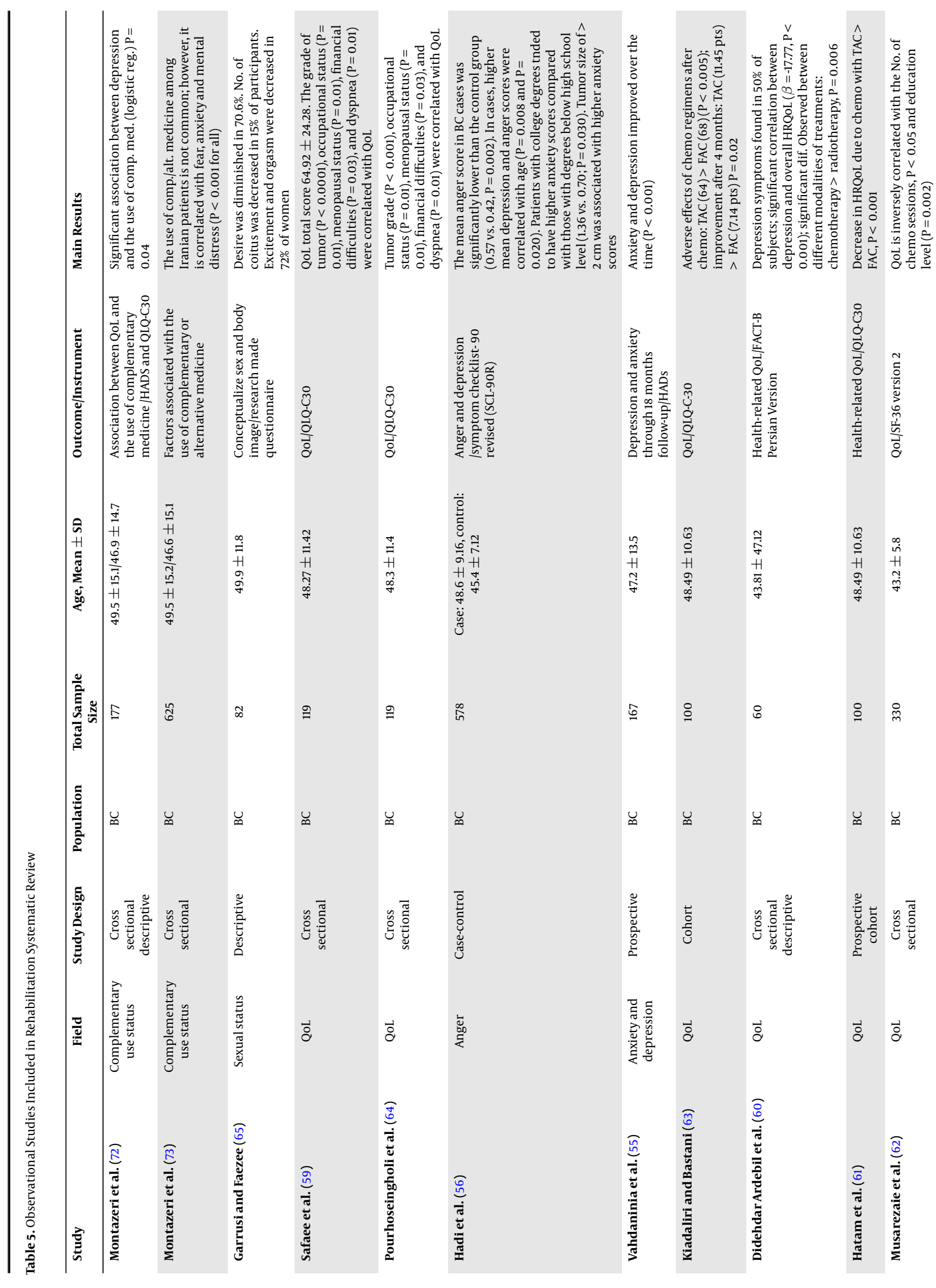



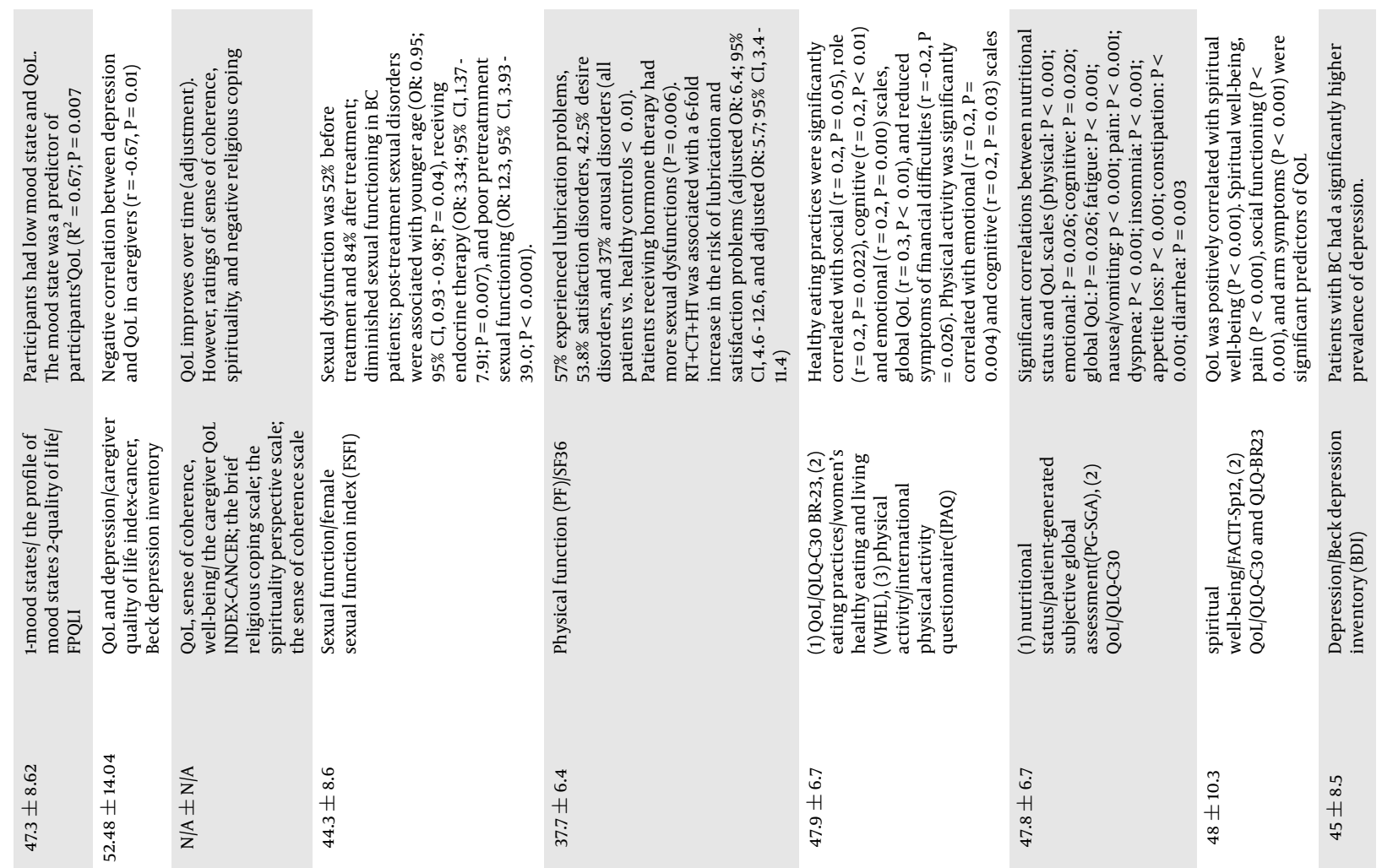

$\hat{b}$
+1
$a$
$\stackrel{4}{9}$

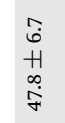

20
$\infty$
H
2
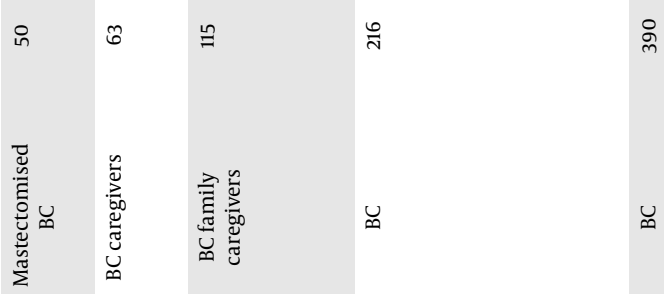

@

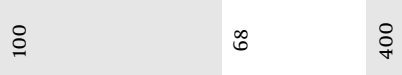

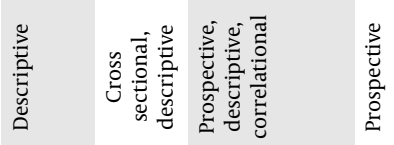

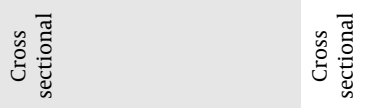

菢芯

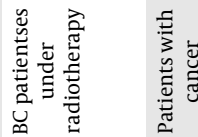

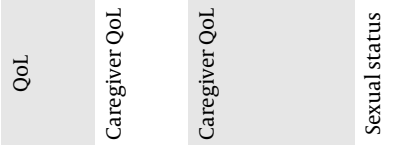
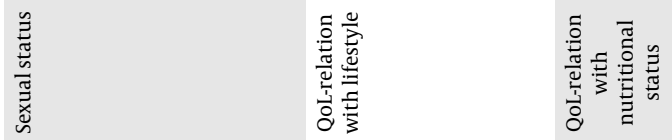

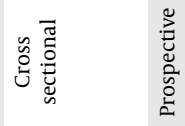
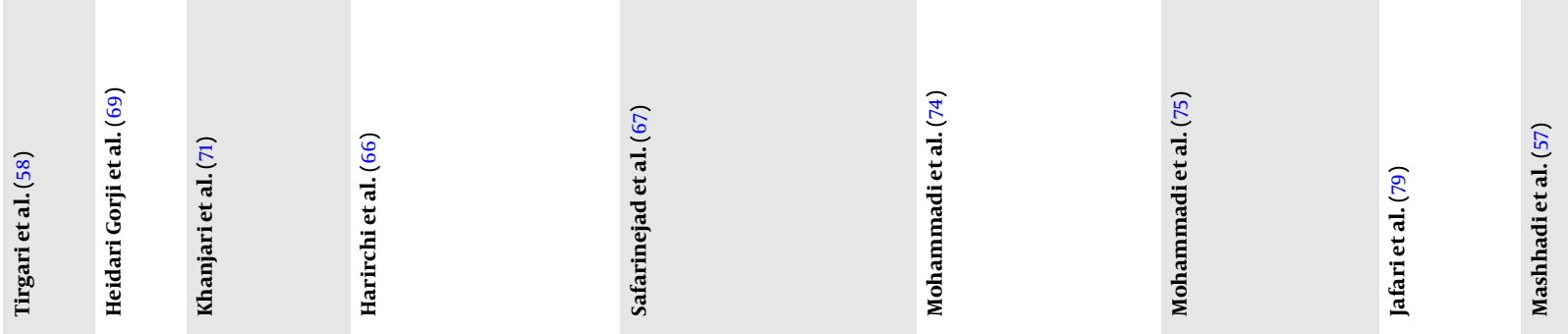

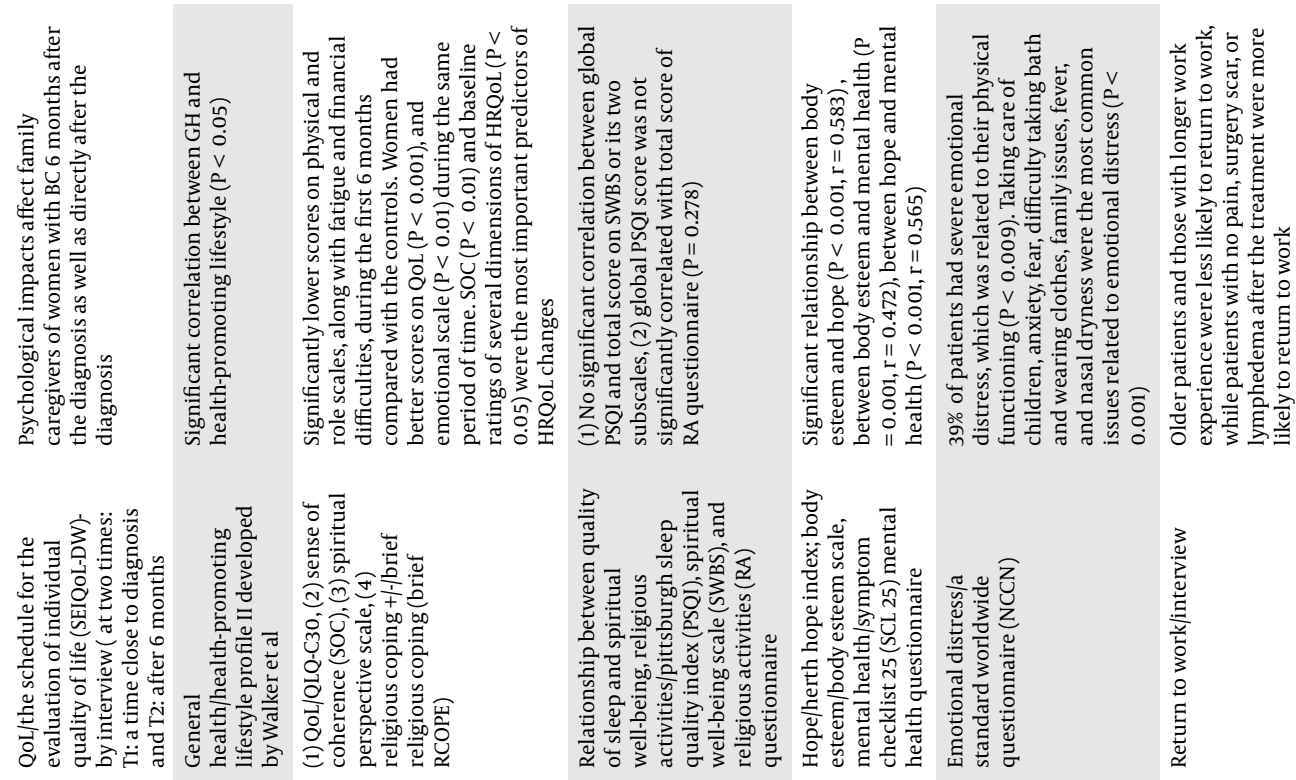

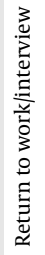
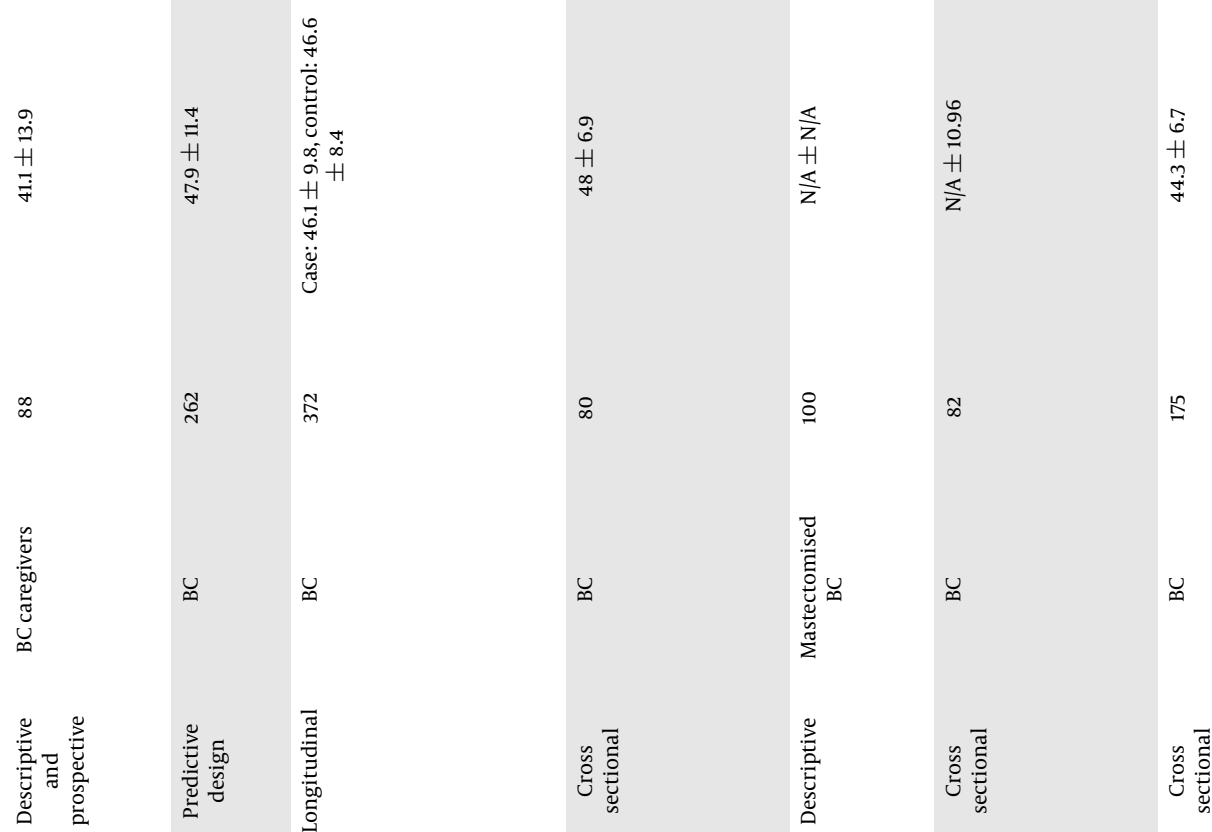

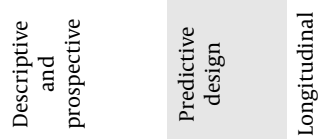
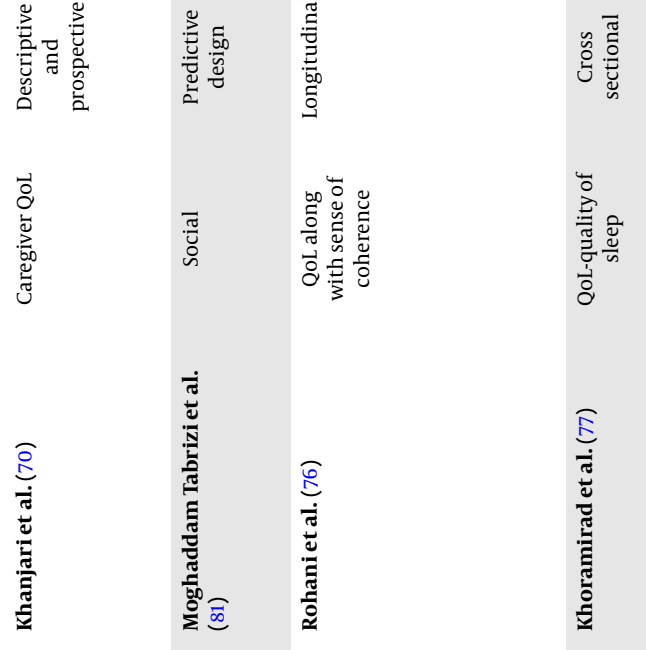

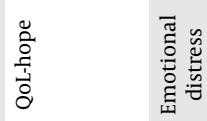

흄

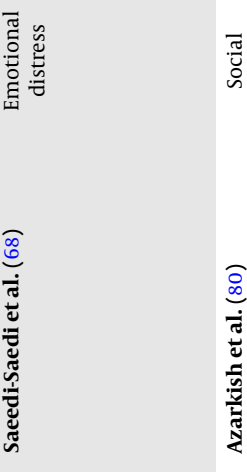

